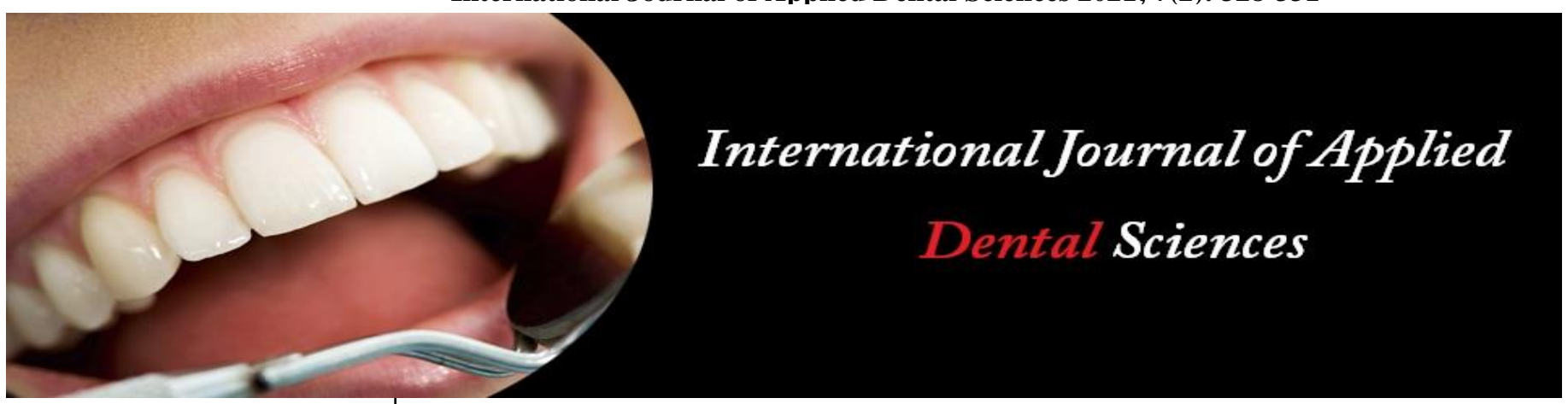

ISSN Print: 2394-7489

ISSN Online: 2394-7497

IJADS 2021; 7(2): 328-331

(C) 2021 IJADS

www.oraljournal.com

Received: 28-02-2021

Accepted: 30-03-2021

Dariela Isabel Gonzalez Guajardo Master in Sciences Student,

Universidad Autonoma de Nuevo Leon, Facultad de Odontologia,

Monterrey, Nuevo Leon, CP 64460 ,

Mexico

Juan Eduardo Arizpe Coronado Professor, Universidad Autonoma de Nuevo Leon, Facultad de

Odontologia, Monterrey, Nuevo Leon, CP 64460, Mexico

Jorge Arturo Gutierrez Longoria Associate Professor, Universidad Autonoma de Nuevo Leon, Facultad de Odontologia, Monterrey, Nuevo Leon, CP 64460, Mexico

Rosendo Carrasco Gutierrez Professor, Benemerita Universidad Autonoma de Puebla, Facultad de Estomatologia, Puebla, Mexico

Maria de los Angeles Moyaho Bernal Professor, Benemerita Universidad Autonoma de Puebla, Facultad de Estomatologia, Puebla, Puebla, Mexico

Maria Argelia Akemi Nakagoshi Cepeda

Professor, Universidad Autonoma de Nuevo Leon, Facultad de Odontologia, Monterrey, Nuevo Leon, CP 64460, Mexico

Juan Manuel Solis-Soto

Professor, Universidad Autonoma de Nuevo Leon, Facultad de

Odontologia, Monterrey, Nuevo Leon, CP 64460, Mexico

Corresponding Author: Juan Manuel Solis-Soto Professor, Universidad Autonoma de Nuevo Leon, Facultad de Odontologia, Monterrey, Nuevo Leon, CP 64460, Mexico

\section{Comparative evaluation of four bioceramic-based endodontic sealers}

\author{
Dariela Isabel Gonzalez Guajardo, Juan Eduardo Arizpe Coronado, \\ Jorge Arturo Gutierrez Longoria, Rosendo Carrasco Gutierrez, Maria de \\ los Angeles Moyaho Bernal, Maria Argelia Akemi Nakagoshi Cepeda and \\ Juan Manuel Solis-Soto
}

DOI: $\underline{\text { https://doi.org/10.22271/oral.2021.v7.i2e.1229 }}$

\section{Abstract}

Introduction: Perforations are characterized by a communication between the root canal system and the external surface of the tooth.

Objective: To analyze the literature on the perforations that can occur during root canal treatment and the different bio ceramic materials used to seal them such as gray MTA, ProRoot MTA, Biodentine and Endo Sequence.

Methodology: Electronic bibliographic databases (PubMed, EBSCO, Cochrane) were used using the keywords perforations, bioceramics, MTA, ProRoot MTA, Biodentine, EndoSequence.

Results: MTA was the first bioceramic cement, providing good sealing, biocompatibility, and antimicrobial activity. However, it has been demonstrated that new bio ceramic cements have a better sealing capacity. ProRoot MTA is an excellent choice for sealing mainly furcated holes, a disadvantage is the change of color in the pieces. Biodentine, a biocompatible calcium silicate-based bio ceramic cement used in endodontic treatments, provides better sealing capabilities than other bio ceramic cements. Endosequence is a new bio ceramic cement, it can be found as a pre-mixed putty making it easier for the operator to handle, in addition, its sealing capacity is better compared to other bio ceramic cements. Conclusion: According to the literature reviewed, Biodentine and EndoSequence are the best bio ceramic materials for sealing and repairing endodontic holes.

Keywords: MTA", "ProRoot MTA", "Biodentine”, “endo sequence

\section{Introduction}

Perforations are characterized by a communication between the root canal system and the external surface of the tooth ${ }^{[1]}$ and occur during root canal treatment and may represent up to $10 \%$ of the cases that fail ${ }^{[2]}$. Attempting to locate canals after calcified metamorphosis and negotiating them at full working length can lead to perforation ${ }^{[3]}$, as well as misalignment of drills during access preparation or during root canal instrumentation. Some are created during post space preparation ${ }^{[4]}$. When a perforation occurs, it invades the supporting structures causing inflammation and bone resorption, which in turn compromises the health of the periradicular tissues and the prognosis of the tooth. Effective management of perforations depends on many factors, including early diagnosis, size, shape, location, and treatment choice [5]. Perforations can lead to complications requiring extraction of the affected tooth ${ }^{[4]}$. A variety of materials have been suggested for the repair of perforations ${ }^{[6]}$. Bioceramics are among the materials recently introduced in endodontics, they are inorganic and non-metallic materials, they are biocompatible or metallic oxides with improved sealing capacity, antibacterial and antifungal activity. They have the ability to function as human tissues or to reabsorb and stimulate the regeneration of natural tissues. This biocompatibility is attributed to the presence of calcium phosphate, as it is also the main inorganic component of hard tissues such as teeth and bones ${ }^{[7]}$. During endodontic treatment iatrogenies, such as perforations, can occur, effective management consists of early detection and sealing of the perforation, as well as the use of a bioceramic material that provides a good seal and that also its biocompatibility 
helps stimulate tissue regeneration. The objective of the study is to analyze the literature on the different bioceramic materials used to seal perforations that occur during endodontic treatment, such as gray MTA, ProRoot MTA, Biodentine and Endosequence, so that the dentist knows more about these materials and can select the appropriate one when a situation such as a perforation occurs.

\section{Materials and Methods}

Articles on the subject published through the PubMed, SCOPUS and Google Scholar databases were analyzed, with emphasis on the last 5 years. The quality of the articles was evaluated using PRISMA guidelines, i.e., identification, review, choice and inclusion. The quality of the reviews was assessed using the measurement tool for evaluating systematic reviews (AMSTAR-2). The search was performed using Boolean logical operators AND, OR and NOT. It was realized with the words "MTA", "ProRoot MTA", "Biodentine", "Endosequence". The keywords were used individually, as well as each of them related to each other.

\section{Results \& Discussion \\ 3.1 MTA gray}

Mineral trioxide aggregate (MTA) is a calcium silicate-based cement (CSC) commonly used in endodontic procedures ${ }^{[8]}$ such as in apical surgery, in non-surgical treatments such as direct pulp capping, as a temporary filling material, in root canal repair or bifurcation and apexification ${ }^{[9]}$. Among its advantages is the reduced treatment time, good sealing capacity, biocompatibility, bioactivity, and its antibacterial activity ${ }^{[10]}$. It also stimulates the expression of proteins associated with the formation of a mineralized tissue similar to cement ${ }^{[11]}$.

MTA has a high potential in borehole repair as it demonstrates normal healing in short/long-term clinical outcomes ${ }^{[12]}$. It promotes appropriate peri radicular tissue reactions for sealing a borehole ${ }^{[13]}$. It is also cost effective and readily available ${ }^{[14]}$ however, Portland cement provides a more effective seal for furcated holes and can be considered a more economical substitute for MTA as a repair material ${ }^{[15]}$. A clinical case report in which MTA was placed immediately after the puncture was detected. The patient was consistent at his follow-up appointments and 10 years later, no pain, normal periodontal probing, and no radiolucent area was detected in the region of the perforation, evidencing successful tooth repair ${ }^{[16]}$.

MTA was the first bioceramic cement used in endodontic treatments. Thanks to its good sealing capacity, biocompatibility, and antimicrobial activity, it provides a better prognosis for teeth that have suffered from perforation; however, recent studies have shown that new bioceramic cements have a better sealing capacity.

\subsection{ProRoot MTA}

Composed mainly of tricalcium silicate, dicalcium silicate, tricalcium aluminate, tetra-calcium aluminoferrite and bismuth oxide. It has the ability to stimulate the formation of the dentin bridge leading to the healing of the pulp [17]. Exposure in an acid environment promotes the release of $\mathrm{Si}$ and $\mathrm{Ca}$ ions, observing optimal biological properties in terms of cell viability ${ }^{[18]}$

ProRoot MTA has shown a better marginal adaptation than Angelus MTA, when mechanically mixed it has better handling characteristics ${ }^{[19]}$, it seems to be superior to OrthoMTA and Endocem MTA in terms of biological properties [20] and it has shown higher values of bonding strength than EndoSeal MTA, and therefore, it is a better choice for root canal repair, as well as in primary molar furcation repair ${ }^{[21]}$, however Biodentine showed considerable performance as a hole repair material than ProRoot MTA even after exposure to various endodontic chelating agents ${ }^{[22]}$. ProRoot MTA is more successful in preventing bacterial leakage ${ }^{[23]}$. One disadvantage is the discoloration of teeth due to bismuth oxide content ${ }^{[24]}$.

ProRoot MTA is an excellent choice for sealing mainly furcated holes, it has optimal biological properties in terms of cell viability. One of its disadvantages is the change in color that it can cause in the pieces and in addition in diverse comparative studies it is mentioned that the Biodentine has a better capacity of sealing reason why it would be a better option to consider.

\subsection{Biodentine}

It is a bioactive cement based on calcium silicate, was launched on the dental market as a "dentin substitute". This biologically active material helps its penetration through the dentin tubules to crystallize intertwined with the dentin and provide mechanical properties ${ }^{[9]}$. It is biocompatible, as it was observed to involve molecules that induce the formation of mineralized tissue, with expression of ALP and OPN mineralization markers, without interference in the number of osteoclasts ${ }^{[11]}$ and non-toxic as tested in human pulp cells and provides a marginal seal by adhering to both dentin and enamel ${ }^{[17]}$.

Very good results have been obtained when used to seal a furcation hole in permanent molars ${ }^{[13],[25]}$ as well as in temporary molars ${ }^{[26]}$, therefore, it should be considered as a promising alternative ${ }^{[13]}$. It has shown greater resistance to dislocation than ProRoot MTA as a borehole repair material [27], better sealing capacity compared to other root repair materials ${ }^{[28-30]}$, and also less swelling, less volume of extruded material, and greater repair [31]. However, the periapical acidic environment may jeopardize the solubility of Biodentine, which affects its sealing characteristics as in repair procedures in apical root borings ${ }^{[32]}$.

Biodentine is an excellent bioceramic cement based on calcium silicate, biocompatible, used very frequently in endodontic treatments such as sealing of coronal and root perforations, apical plugs etc., has demonstrated to have a better sealing capacity than other bioceramic materials and therefore is considered a very good alternative to use.

\subsection{EndoSequence}

EndoSequence is a bioceramic premixed putty, thickened with tricalcium silicate, zirconium oxide, tantalum pentoxide, dicalcium silicate, calcium sulphate and monobasic calcium phosphate. Its setting time is less than $2 \mathrm{~h}^{[33]}$. The consistency of putty provides a better apatite forming capacity, this property can be beneficial to improve its sealing capacity for the root canal dentin ${ }^{[34]}$. It is a biocompatible material ${ }^{[35]}$. Its constitution is not affected by the presence of moisture ${ }^{[36]}$.

Endosequence has shown improved sealing ability compared to other root repair materials ${ }^{[37-39]}$ mainly in the coronal and mid-coronal portion of the root canal ${ }^{[40]}$.

Endosequence is a new bioceramic cement, it can be found in different presentations one of them is in premixed putty which provides several characteristics one of them is that it facilitates the operator's manipulation during the sealing of perforations at root level, in addition, its sealing capacity has been better compared to other bioceramic materials 


\section{Conclusions}

Perforations occur during endodontic treatment and a variety of materials have been suggested for repair. MTA was the first bio ceramic cement, among its advantages is its sealing ability, biocompatibility and antimicrobial activity, however it has been shown that other cements have better sealing ability. ProRoot MTA is an excellent option for sealing furcated holes, but a disadvantage is the change of color in the pieces. Biodentine has proven to have better sealing capabilities than other bioceramic materials, as well as the Endosequence which can be found as a premixed putty making it easier to handle.

\section{References}

1. Estrela C, de Alemida-Decurcio D, Rossi-Fedele G, Almeida-Silva J, Aguirre-Guedes O, Henrique-Borges A. Root perforations: a review of diagnosis, prognosis and materials. Braz Oral Res 2018;18(32):e73.

2. Mohammed-Saed S, Ashley MP, Darcey J. Root perforations: aetiology, management strategies and outcomes. The hole truth. Br Dent J. 2016;220(4):171180.

3. Haider-Siddiqui S, Nabil-Mohamed A. Calcific Metamorphosis: A Review. Int J Heatlh Sci (Qassim) 2016;10(3):437-442.

4. Siew K, Lee AHC, Cheung GSP. Treatment Outcome of Repaired Root Perforation: A Systematic Review and Meta-analysis. J Endod 2015;41(11):1795-804.

5. Gorni FB, Andreano A, Ambrogi F, Bramdilla E, Gagliani M. Patient and Clinical Characteristics Associated with Healing of Iatrogenic Perforations after Root Canal Treatment: Results of a Long-term Italian Study. J Endod 2016;42(2):211-215.

6. Bezerra-Silva LA, Grecca-Pieroni KAM, Nelson-Filho P, Bezerra-Silva RA, Hernandéz-Gatón P, PacíficoLucisano $\mathrm{M}$ et al. Furcation Perforation: Periradicular Tissue Response to Biodentine as a Repair Material by Histopathologic and Indirect Immunofluorescence Analyses. J Endod. 2017;43(7):1137-1142.

7. Al-Haddad A, Che Ab-Aziz ZA. Bioceramic-Based Root Canal Sealers: A Review. Int J Biomater 2016;9(53):97110.

8. Dawood AE, Parashos P, Wong RHK, Reynolds EC, Manton DJ. Calcium silicate-based cements: composition, properties, and clinical applications. J Investig Clin Dent 2017;8(2):10-15.

9. Kaur M, Singh H, Singh-Dhillon J, Batra M, Saini M. MTA versus Biodentina: Review of Literature with a Comparative Analysis. J Clin Diagn Res 2017;11(8):0105 .

10. Kandemir-Demirci G, Kaval ME, Caliskan MK. Treatment of Immature teeth with nonvital pulps in adults: a prospective comparative clinical study comparing MTA with $\mathrm{Ca}(\mathrm{OH}) 2$. Int Endod J. 2020;53(1):15-18.

11. Silva RAB, Borges ATN, Hernández-Gatón $\mathrm{P}$, de Queiroz AM, Arzate H, Romualdo PC et al. Histopathological, histoenzymological, immunohistochemical and Immunofluorescence analysis of tissue response to sealing materials after furcation Perforation. Int Endod J 2019;52(10):1489-1500.

12. Hosoya N, Takigawa T, Horie T, Maeda H, Yamamoto $\mathrm{Y}$, Momoi $\mathrm{Y}$ et al. A review of the literature on the Efficacy of mineral trioxide aggregate in conservative dentistry. Dent Mater J 2019;38(5):693-700.
13. Sousa-Reis M, Kochenborger-Scarparo R, Steier L, Poli de Figueiredo JA. Periradicular Inflammatory response, bone resorption, and cementum Repair after sealing of Furcation Perforation with mineral trioxide aggregate (MTA Angelus) or Biodentine. Clin Oral Investig. 2019;23(11):4019-4027.

14. Kumar-Lagisetti A, Hegde P, Nidarsh-Hegde M. Evaluation of bioceramics and zirconia-reinforced glass ionomer cement in Repair of Furcation perforations: An in vitro study. J Conserv Dent 2018;21(2):184-189.

15. Reddy NV, Srujana P, Daneswari V, Konyala HR, Mareddy AR, Mohammad N. Sealing Ability of MTA vs Portland Cement in the Repair of Furcal Perforations of Primary Molars: A Dye Extraction Leakage Model-An In Vitro Study. Int J Clin Pediatr Dent. 2019;12(2):83-87.

16. Cosme-Silva L, Carnevalli B, Thiemy-Sakai V, VianaViola N, Franco-de Carvalho L, Franco-de Carvalho EM. Radicular Perforation Repair with Mineral Trioxide Aggregate: A Case Report with 10-Year Follow-up. Open Dent J 2016;30(10):733-738.

17. Bakhtiar H, Hossein-Nekoofar M, Aminishakib P, Abedi F, Naghi-Moosavi F, Esnaashari E, et al. Human Pulp Responses to Partial Pulpotomy Treatment with TheraCal as Compared with Biodentine and ProRoot MTA: A Clinical Trial. J Endod 2017;43(11):1786-1791.

18. Collado-González M, López-García S, García-Bernal D, Oñate-Sánchez RE, Tomás-Catalá CJ, Moraleda JM, et al. Biological effects of acid-eroded MTA Repair HP and ProRoot MTA on human periodontal ligament stem cells. Clin Oral Investig 2019;23(10):3915-3924.

19. Nihal-Sisli S, Ozbas H. Comparative Micro-computed Tomographic Evaluation of the Sealing Quality or ProRoot MTA and MTA Angelus Apical Plugs Places with Various Techniques. J Endod 2017;43(1):147-151.

20. Kim M, Yang W, Kim H, Ko H. Comparison of the Biological Properties of ProRoot MTA, OrthoMTA, and Endocem MTA Cements. J Endod 2014;40(10):16491653.

21. Haghgoo R, Abbasi F. Treatment of Furcal Perforation of Primary Molars with ProRoot MTA versus Root MTA: A Laboratory Study. Iran Endod J. 2013;8(2):52-54.

22. Prasanthi P, Garlapati R, Nagesh B, Sujana V, KiranNaik KM, Yamini B. Effect of $17 \%$ ethylenediaminetetraacetic acid and $0.2 \%$ chitosan on pushout bond strength of Biodentine and ProRoot mineral trioxide aggregate: An in vitro study. J Conserv Dent. 2019;22(4):387-390.

23. Övsay E, Kaptan RF, Sahin F. The Repair of Furcal Perforations in Different Diameters with Biodentine, MTA, and IRM Repair Materials: A Laboratory Study Using an E. Faecalis Leakage Model. Biomed Rest Int. 2018;15(20):54-78.

24. Shin-Hong K, Young-Seob S, Hyo-Seol Lee, Shin Y, IlYoung J, Je-Seon S. Color Changes of Teeth after Treatment with Various Mineral Trioxide Aggregatebased Materials: An Ex Vivo Study. J Endod. 2015;41(5):737-741.

25. Alazrag MA, Abu-Seida AM, El-Batouty KM, El-Ashry SH. Marginal adaptation, solubility and biocompatibility of TheraCal LC compared with MTA-angelus and biodentine as a furcation Perforation Repair material. BMC Oral Health 2020;20(1):298.

26. Ramazani N, Sadeghi P. Bacterial Leakage of Mineral Trioxide Aggregate, Calcium-Enriched Mixture and Biodentine as Furcation Perforation Repair Materials in 
Primary Molars. Iran Endod J. 2016;11(3):214-218.

27. Nagas E, Kucukkaya S, Eymirli A, Ozgur Uyanik M, Cavit-Cehreli Z. Effect of Laser-Activated Irrigation on the Push-Out Bond Strength of ProRoot Mineral Trioxide Aggregate and Biodentine in Furcal Perforations. Photomed Laser Surg 2017;35(4):231-235.

28. Chandrakant-Sinkar E, Patil SS, Jogad NP, Gade VJ. Comparison of sealing Ability of ProRoot MTA, RetroMTA, and Biodentine as furcation Repair materials: An ultraviolet spectropgotometric analysis. J Conserv Dent 2015;18(6):445-448.

29. Samuel A, Asokan S, Geetha-Priya PR, Thomas S. Evaluation of sealing Ability of Biodentine and mineral trioxide aggregate in primary molars using scanning electron microscope: A randomized controlled in vitro trial. Contemp Clin Dent 2016;7(3):322-325.

30. Sinkar RC, Patil SS, Jogad NP, Gade VJ. Comparison of sealing Ability of ProRoot MTA, RetroMTA, and Biodentine as furcation Repair materials: An ultraviolet spectrophotometric analysis. J Conserv Dent. 2015;18(6):445-448.

31. Cardoso M, Anjos-Pires MD, Correlo V, Reis R, Paulo M, Viegas C. Biodentine for Furcation Perforation Repair: An Animal Study with Histological, Radiographic and Micro-Computed Tomographic Assessment. Iran Endod J 2018;13(3):323-330.

32. Pushpa S, Maheshwari C, Maheshwari, Sridevi N, Duggal P, Ahuja P. Effect of $\mathrm{pH}$ on solubility of White Mineral Trioxide Aggregate and Biodentine: An in vitro study. J Dent Rest Dent Clin Dent Prospects. 2018;12(3):201-207.

33. Mahgoub N, Alqadasi B, Aldhorae K, Assiry A, Altawili ZM, Hong T. Comparison between iRoot BP Plus (EndoSequence Root Repair Material) and Mineral Trioxide Aggregate as Pulp-capping Agents: A Systematic Review. J Int Soc Prev Community Dent. 2019;9(6):542-552.

34. Abu-Zeid ST, Alamoudi RA, Abou-Neel EA, MokeemSaleh AA. Morphological and Spectroscopic Study of an Apatite Layer Induced by Fast-Set Versus Regular-Set EndoSequence Root Repair Materials. Material (Basel). 2019;12(22):36-78.

35. Willershausen I, Callaway A, Briseño B, Willershausen B. In vitro analysis of the cytotoxicity and the antimicrobial effect of four endodontic sealers. Head Face Med 2011;10(7):15-17.

36. Al-Haddad AY, Kutty MG, Abu-Kasim NH, Ab-Aziz ZAC. The effect of moisture conditions on the constitution of two bioceramic-based root canal sealers. J Dent Sci 2017;12(4):340-346.

37. Jeevani E, Jayaprakash T, Bolla N, Vemuri S, Ram-Sunil C, Kalluru RS. Evaluation of sealing Ability of MMMTA, Endosequence, and biodentine as furcation Repair materials: UV spectrophotometric analysis. J Conserv Dent 2014;17(4):340-343.

38. Antunes HS, Gominho LF, Andrade-Junior CV, Dessaune-Neto N, Alves FRF, Rocas IN et al. Sealing Ability of two root-end filling materials in a Bacterial nutrient leakage model. Int Endod J 2016;49(10):960965.

39. Nagesh B, Jeevani E, Sujana V, Damaraju B, Sreeha K, Ramesh P. Scanning electron microscopy (SEM) evaluation of sealing Ability of MTA and EndoSequence as root-end filling mterials with chitosan and carboxymethyl chitosan (CMC) as retrograde smear layer removing agents. J Conserv Dent 2016;19(2):143-146.

40. Huang Y, Orhan K, Celikten B, Orhan AI, Tufenkci P, Sevimay S. Evaluation of the sealing Ability of different root canal sealers: combined SEM and micro-CT study. J Appl Oral Sci 2018;15(26):16-20. 